\title{
25-Hydroxyvitamin D and Total Calcium: Extraordinarily Low Plasma Concentrations in Saudi Mothers and Their Neonates
}

\author{
SALAH ALI TAHA, SAGIDA M. DOST, AND SALEH H. SEDRANI ${ }^{(27)}$ \\ College of Medicine and Consultant to University Hospitals [S. A. T.], Neonatal Unit, King Abdul Aziz \\ University Hospital [S. M. D.], and Department of Biochemistry, College of Science [S. H. S.], King Saud \\ Universiy, Riyadh, Saudi Arabia
}

\begin{abstract}
Summary
Venous blood was obtained from 100 consecutive and unselected Saudi Arabian mothers and their neonates within $48 \mathrm{~h}$ after delivery. Plasma levels of 25-hydroxyvitamin D (25-OHD) and total calcium were measured in paired samples. Fifty-nine mothers and 70 neonates had subnormal (less than $10 \mathrm{ng} / \mathrm{ml}$ ) 25OHD levels. Plasma Ca concentrations were low in $61 \%$ of the mothers and $59 \%$ of the newborns consisting of 10 preterm and 38 full term babies. There were significant correlation between the plasma levels of maternal and neonatal 25-OHD $(r=0.54$; $P=0.0001)$, maternal 25-OHD and $\mathrm{Ca}(r=-0.22 ; P=0.03)$, neonatal 25-OHD and $\mathrm{Ca}(r=-0.28 ; P=0.0009)$, and maternal and neonatal calcium levels $(r=0.46 ; P=0.0001)$. Nevertheless, maternal 25-OHD was not invariably higher than that in the infant. Normocalcemia was observed in 29 neonates and 26 mothers (20 mother/baby pairs) in the presence of subnormal maternal 25-OHD. Twenty babies and 16 mothers including nine mother/baby pairs had hypocalcemia in the presence of normal levels of 25-OHD. This indicates that vitamin D plays a crucial, but not exclusive, role in calcium homeostasis during pregnancy.

This study revealed that vitamin $D$ deficiency is very prevalent during pregnancy in Saudi Arabia. It also showed that asymptomatic hypocalcemia in full term babies is far commoner than is generally appreciated. It is considered that vitamin D deficiency is primarily due to lack of exposure to sunlight. Encouragement to obtain sunlight exposure and fortification of food are the only alternative measures.
\end{abstract}

\section{Abbreviation}

25-OHD, 25-hydroxyvitamin D

Saudis, especially women, avoid exposure to sunlight due to cultural and traditional beliefs. Ultraviolet light has been shown to produce changes in circulating 25-OHD equivalent to those produced by a daily dose of $10,000 \mathrm{IU}$ i.e. several times the recommended daily adult intake in food (21). Second, the dietary intake of vitamin D by Saudi Arabians has been shown to be far below the amount recommended by FAO/WHO, in the United States and in the United Kingdom $(20,24)$.

In spite of abundant sunlight throughout the year, several vitamin $\mathrm{D}$ deficiency diseases have been reported in Saudi Arabia, including rickets $(8,9)$, fractures of the head of the femur in the elderly, and osteomalacia (24). We have noticed a strikingly high incidence of hypocalcemia in full term infants delivered at King Abdul Aziz University Hospital. In view of the wide prevalence of vitamin $\mathrm{D}$ deficiency diseases, we sought to define the role of this vitamin in the pathogenesis of neonatal hypocalcemia. Since 25-OHD is the major circulating form of vitamin D and since its plasma concentrations directly reflect its status (6), we opted to measure this metabolite and total calcium concentrations in mothers and their neonates.

\section{PATIENTS AND METHODS}

Clinical. A 5-ml sample of venous blood was taken from each of 100 unselected mothers and $2 \mathrm{ml}$ from their corresponding babies, within $48 \mathrm{~h}$ of delivery at King Abdul Aziz University Hospital for estimation of plasma 25-OHD and total calcium levels. Informed consent was obtained from all mothers before venous samples of blood were drawn.

Information was obtained on diet during pregnancy, iron and vitamin supplementation, and the family socioeconomic status. Parity, type of delivery, and sex of the neonate were noted. Parity was classified into three groups: primiparous, multiparous 1-4, and grand multiparous (having from 5-9 siblings).

Weight and other anthropometric measurements were taken as soon after birth as the neonate's condition would allow. Gestational age was evaluated clinically using the Ballard et al. (1) scoring system, a modification of the Dubowitz scale. Appropriateness of weight for gestational age was determined from Gairdner and Pearson standards (10). Preterm and term newborns were classified as appropriate for date, small for date, or large for date.

Biochemical methods. Plasma was separated and stored at $-20^{\circ} \mathrm{C}$ until analysis. Total serum calcium was measured by colorimetric methods (Boehringer Mannheim GmbH, Diagnostica). Serum 25-OHD was quantitated by competitive proteinbinding assay using rachitic rat serum as described by Edelstein et al. (7). The percentage of the overall recovery of added ${ }^{3} \mathrm{H}-$ labeled 25-hydroxyvitamin $\mathrm{D}_{3}$ (Amersham International, U. K.) was $79.8 \pm 3.90$.

Calculation and statistical methods. Results are expressed as means \pm SD and ranges. Statistical analysis utilized Pearson's correlation coefficient $(r)$ and calculation of probability ( $P$ value).

Normal total calcium levels for both mother and full term neonate are taken as $8.5-10.5 \mathrm{mg} / 100 \mathrm{ml}$. 25-OHD normal levels are considered to be $10-57 \mathrm{ng} / \mathrm{ml}$ (11).

\section{RESULTS}

Clinical. Women in this study group belonged, socioeconomically, to the middle strata of Saudi Arabian society. Their account of diet during pregnancy was, however, vague but they all claimed to have had a mixed diet with iron and folic acid 
(Fefol), but no vitamin D supplements. Vitamin D intake was estimated at 50-70 IU/day, which compared very unfavorably with the daily recommended dose during pregnancy $(16,17)$.

The 100 pregnant women were all delivered of single babies; 84 had spontaneous vaginal delivery, 5 forceps, 1 ventose extraction, and 10 cesarean section. Thirty-five were primiparous; 45 had $1-4$ and 20 had 5-9 children. Of the newborns, 43 were males and 57 were females. Gestational ages and weights of neonates are shown in Table 1.

Two of the hypocalcemic infants had convulsions but the others were given calcium and vitamin $\mathrm{D}$ before this development could occur.

Biochemical Results. Maternal and neonatal plasma 25-OHD levels. These findings are shown in Table 2. In eight mothers and in five mother-neonate combinations, plasma 25-OHD was undetectable, and one had an unusually high level $(160 \mathrm{ng} / \mathrm{ml})$. This particular mother had preeclamptic toxemia and deep vein thrombosis for which she was given heparin. Her baby was large for age and had normal plasma 25-OHD but both mother and child were hypocalcemic.

Maternal plasma 25-OHD was higher than in the neonates in only 44 cases, lower in 25 , and equal in the remainder. The results did not show any significant effect of parity on 25-OHD or calcium levels.

In 12 neonates, the levels of 25-OHD were unrecordable (Table 2). Twenty-nine babies were normocalcemic in the presence of subnormal plasma $25-\mathrm{OHD}$ values. On the other hand, 20 neonates who had normal 25-OHD levels were hypocalcemic. Nine mother and newborn pairs had normal calcium levels under subnormal 25-OHD plasma concentrations. Sex of the infant, gestational age, weight, and parity had no effect on the neonates' 25-OHD level.

Maternal and neonatal total plasma calcium concentrations. These results are shown in Table 3. Twenty-six mothers who had low 25-OHD were normocalcemic. On the other hand, 16 mothers who had normal 25-OHD levels were hypocalcemic.

All the preterms were hypocalcemic. There were no significant differences between calcium levels in the term or preterm infants. Again, sex, gestational age, weight, or birth order had no impact on the calcium level of the neonate.

Table 1. Gestational ages and weights of neonates studied*

\begin{tabular}{llllllll}
\hline & \multicolumn{3}{c}{ Gestation age (weeks) } & & \multicolumn{3}{c}{ Weight (kg) } \\
\cline { 2 - 3 } \cline { 6 - 7 } \cline { 5 - 7 } & Mean & SD & Range & & Mean & SD & Range \\
\hline Preterm (10) & & & & & & \\
AFD (8) & 34.5 & $(0.4)$ & $31-36$ & & 2.54 & $(0.38)$ & $1.8-3.1$ \\
SFD (2) & 34.5 & & $34-35$ & & 1.99 & & $1.9-2.08$ \\
LFD (0) & & & & & & \\
Term (90) & & & & & & \\
AFD (81) & 39.3 & $(0.1)$ & $37-42$ & & 3.21 & $(0.11)$ & $2.70-3.90$ \\
SFD (4) & 39 & $(0.6)$ & $38-40$ & & 2.58 & $(0.57)$ & $2.4-2.76$ \\
LFD (5) & 39.4 & $(0.5)$ & $38-42$ & & 4.29 & $(0.5)$ & $4-4.7$ \\
Total = 100 & & & & & &
\end{tabular}

*AFD, appropriate for date; SFD, small for date; LFD, large for date.

Table 2. Levels of 25-OHD in mothers and neonates

\begin{tabular}{clllllllll}
\hline & \multicolumn{4}{c}{$\begin{array}{c}\text { Mother } \\
(n=100)\end{array}$} & & \multicolumn{4}{c}{$\begin{array}{c}\text { Neonates } \\
(n=100)\end{array}$} \\
\cline { 2 - 5 } \cline { 5 - 8 } Level $(\mathrm{ng} / \mathrm{ml})$ & $n$ & Mean & SD & Range & & Mean & SD & Range \\
\hline$\leqslant 10$ & 59 & 3.6 & $(2.9)$ & $0-9.9$ & 70 & 3.6 & $(3)$ & $0-9.7$ \\
$10-57$ & 40 & 27.3 & $(13)$ & $10-57$ & 28 & 21.4 & $(10.6)$ & $10-45.7$ \\
55 & $1^{*}$ & 160 & & 160 & & 62 & $(3)$ & $59-65$ \\
Total & 100 & & & & 100 & & & \\
\hline
\end{tabular}

${ }^{*}$ Excluded, see text.
Table 3. Maternal and neonatal calcium levels

\begin{tabular}{lcccc}
\hline & \multicolumn{4}{c}{$\leqslant 8.5 \mathrm{mg} / \mathrm{dl}$ calcium } \\
\cline { 2 - 5 } & $n$ & Mean & SD & Range \\
\hline Mothers $(n=96)$ & 59 & 7.66 & $(0.13)$ & $6.2-8.4$ \\
& 37 & 9.42 & $(0.17)$ & $8.5-10.6$ \\
Neonates $(n=82)$ & 48 & 7.62 & $(0.15)$ & $6-8.4$ \\
& 34 & 9.87 & $(0.17)$ & $8.5-11.3$ \\
\hline
\end{tabular}

Correlations between maternal and neonatal plasma levels of 25-OHD and calcium. Table 4 shows the substantial correlation between mothers' and newborns' 25-OHD plasma levels $(P=$ $0.0001)$ and between their total calcium levels $(P=0.0001)$.

\section{DISCUSSION}

This study was conducted in Riyadh (latitude, $24^{\circ}, 42 \mathrm{~N}$ ), Saudi Arabia, during the winter months. However, seasonal variations of vitamin $D$ biosynthesis are not expected in this subtropical country (19). The populace of Saudi Arabia, particularly females, children up to about 2 years of age, and elderly people, is minimally exposed to the sun $(8,20,24)$.

In this study, diet, which is in any case a poor source of vitamin D (16), has been found to be particularly deficient in supplying vitamin $\mathrm{D}$. The plasma levels of $25-\mathrm{OHD}$ in normal Saudis had been found to be very low $(20,24)$. Low mean concentrations of $25-\mathrm{OHD}$ were also demonstrated in 30 mothers and cord blood (2). Westerners living in Saudi Arabia were found to have normal levels of 25-OHD in contrast to normal Saudis (24).

In the present study, plasma 25-OHD was found to be subnormal (less than $10 \mathrm{ng} / \mathrm{ml}$ ) in $59 \%$ of mothers and $70 \%$ of neonates. These figures which indicate severe vitamin D depletion on a large scale are to some degree hidden by the means shown in Table 4 because of the high standard deviation and wide ranges.

The substantial correlation we found between maternal and neonatal concentrations of plasma 25-OHD has also been demonstrated by several investigators $(3,13,14)$. These authors and others stress that the cord values are invariably lower than the maternal levels. Our findings did not reveal the same consistency; 26 mothers had lower 25-OHD values than their neonates. This finding is in agreement with the observation of Belton et al. (2) who demonstrated that the mean circulating levels of 25-OHD is higher in infants than the maternal concentrations of the metabolite. As the transfer rates of vitamin $\mathrm{D}_{3}$ and $25-\mathrm{OHD}_{3}$ across the placenta are comparable (18), it is probable that our infants began to metabolize their own vitamin $D$ at this age.

Plasma calcium concentrations were low in $59 \%$ of the neonates and $61 \%$ of the mothers. Forty mothers and their neonates had such low levels. The relationship was, therefore, not linear, possibly because calcium transfer across the placenta is an active process (5). There was, however, a strong correlation between these two values in mother and neonate $(r=0.46 ; P=0.0001)$. Again, the calcium means of the whole groups underemphasize the severe hypocalcemic states noted in both neonates and mothers. Other workers have not observed the strong correlation between the low levels of plasma calcium and 25-OHD which we are reporting here $(3,4,22)$, particularly in supplemented pregnant women. But the significance of this correlation needs to be substantiated.

In spite of this strong statistical correlation, normocalcemia occurred with subnormal 25-OHD levels in 29 babies and 26 mothers (mother and baby in 20 cases). In the case of the mothers, the most obvious explanation is that they were demineralizing their own bone to maintain a normal calcium homeostasis, in addition to enhanced calcium absorption from the intestine (12). In the case of the fetus, vitamin D metabolites 
Table 4. Maternal and neonatal plasma levels of 25-OHD and total calcium significance of correlation coefficient between values

\begin{tabular}{|c|c|c|c|c|c|c|c|c|c|c|c|c|c|c|c|c|c|c|}
\hline \multirow[b]{3}{*}{ Parameter } & \multirow[b]{3}{*}{$n$} & \multicolumn{3}{|c|}{ Maternal } & \multicolumn{4}{|c|}{ Neonatal } & \multicolumn{10}{|c|}{ Significance of differences between values } \\
\hline & & \multirow[b]{2}{*}{ Mean } & \multirow[b]{2}{*}{$\mathrm{SD}$} & \multirow[b]{2}{*}{ Range } & \multirow[b]{2}{*}{$n$} & \multirow[b]{2}{*}{ Mean } & \multirow[b]{2}{*}{ SD } & \multirow[b]{2}{*}{ Range } & \multicolumn{2}{|c|}{ I \& II } & \multicolumn{2}{|c|}{ I \& III } & \multicolumn{2}{|c|}{ I \& IV } & \multicolumn{2}{|c|}{ II \& IV } & \multicolumn{2}{|c|}{ III \& IV } \\
\hline & & & & & & & & & $r$ & $P$ & $r$ & $P$ & $r$ & $P$ & $r$ & $P$ & $r$ & $P$ \\
\hline $25-\mathrm{OHD}(\mathrm{ng} / \mathrm{ml}) \mathrm{I}$. & 99 & 13.3 & (14.3) & $0-57$ & II.96 & 9.1 & (11.3) & $0-65$ & 0.54 & 0.0001 & -0.22 & 0.03 & -0.25 & 0.018 & -0.28 & 0.009 & 0.46 & 0.0001 \\
\hline Calcium (mg/dl) III. & 96 & 8.2 & $(0.9)$ & $6.2-10.6$ & IV.84 & 8.4 & (1.2) & $6.0-11.3$ & & & & & & & & & & \\
\hline
\end{tabular}

merely enhance the transfer of calcium across the placenta. There must, therefore, be some other mechanism, possibly the active pump, which is keeping the neonates' calcium at normal levels.

This study also revealed that the incidence of asymptomatic hypocalcemia is far more frequent than previously believed. All the preterm neonates were hypocalcemic but 38 full term babies, representing $45 \%$ of the total sample (Table 2 ), were hypocalcemic. Similar observations have been made on the 6th day of life in full term Caucasian neonates, especially during winter, and in Asian pregnant women and their neonates $(3,23)$.

It is not surprising that in this series gestational age had no significant or specific association with either the plasma calcium or the plasma 25-OHD concentrations. Neither did sex, at least in the first $48 \mathrm{~h}$, in contrast to the male sex predominance noted on the 6th day of life by other workers (4).

Plasma 25-OHD and calcium levels were not related to parity. This is in accord with the findings of at least two studies $(4,22)$. The subnormal levels of 25-OHD even of primiparas in this study would seem to indicate a state of severe depletion and lack of storage (15).

We conclude that in spite of abundant sunlight vitamin D deficiency is common in Saudi Arabia, because of minimal exposure to the sun. In addition, women usually go through a continuous cycle of pregnancies and lactation periods which further deplete their stores. Young children are protected indoors till they are independent at about the age of 2 years.

The results of this study highlight the importance of ensuring that pregnant and lactating women are encouraged to expose themselves to natural ultraviolet light and take adequate vitamin D supplements. The requirements of a pregnant woman are probably about 500-700 IU/day (4). We feel that in Saudi Arabia this dose level would be sufficient to maintain adequate level of 25-OHD in mothers. Certainly, improvement of the nutrition status of Saudi mothers during pregnancy will lead in turn to an improvement in the vitamin D status of newborns.

We speculate that, if there is a need for vitamin D supplementation for children, it would be in the range recommended for United States children, that is, $400 \mathrm{IU} /$ day. But, further studies to determine the vitamin $\mathrm{D}$ dose which would maintain plasma 25-OHD within normal levels in mothers, infants, and children are needed.

\section{REFERENCES AND NOTES}

1. Ballard J, Kazmaier K, Driver M 1979 A simple score for assessment of fetal maturation of newly born infants. J Pediatr 95:769

2. Belton NR, Elidrissy ATH, Aldrees A, Elswailin AR, Forfar JO, Barr DGD 1982 Maternal vitamin D deficiency as a factor in the pathogenesis of rickets in Saudi Arabia. In: Norman AW, Shaefer K, Herrath DV, Grigoleit HG (eds): Vitamin D, Chemical, Biochemical Endocrinology of Calcium Metabolism. New York, Walter de Gruyter, pp 735-737

3. Brooke OG, Brown IRF, Bone CDM, Carter ND, Cleeve HJW, Maxwell JD, Robinson VP Winder SM 1980 Vitamin D supplements in pregnant Asian women effects on calcium status and fetal growth. Br Med J 280:751

4. Cockburn F, Belton NR, Purvis RJ, Giles MM, Brower JK, Turner TL Wilkinson EM, Forfar JO, Barie WJM, McKay GS, Pocock SJ 1980Maternal vitamin $\mathrm{D}$ intake and mineral metabolism in mothers and their newborns infants. Br Med J 281:11

5. Cower CL 1956 Radiocalcium studies in pregnancy. Ann N Y Acad Sci 64:28

6. De Luca HF 1978 Vitamin D and calcium transport. Ann NY Acad Sci 307:356 (1978).

7. Edelstein S, Charman M, Lawson DEM, Kodicek E 1974 Competitive protein binding assay for 25-hydroxycholecalciferol. Clin Sci Mol Med 46:231

8. Elidrissy ATH, Taha SA 1980 Rickets in Riyadh. In: Mahjoub E (ed): Proceedings of the 5th Saudi Medical Meeting. Riyadh, Saudi Arabia, College of Medicine, pp 409-418

9. Elidrissy ATH, Sedrani SH 1981 Infantile vitamin D deficiency rickets in Riyadh. Is maternal vitamin D deficiency a possible factor? Calcif Tissue Intr 33:47

10. Gairdner D, Pearson JA 1971 Growth chart for premature and other infants. Arch Dis Child 46:783

11. Haddad JG, Chyu KJ 1975 Competitive protein-binding radioassay of 25hydroxycholecalciferol. J Clin Endocrinol Metab 33:992

12. Heanly RP, Silkman TG 1971 Calcium metabolism during normal human pregnancy. J Clin Endocrinol Metab 33:661

13. Heckmatt JZ, Peacoch M, Davies AEJ, McMurry J, Isherwood DM 1979 Plasma 25-hydroxyvitamin D in pregnant Asian women and their babies. Lancet 2:546

14. Hillman LS, Haddad JG 1974 Human perinatal vitamin D metabolism. I. 25Hydroxyvitamin D in maternal and cord blood. J Pediatr 84:742

15. Mawer EB, Backhouse J, Holman CA, Lumb GA, Stanbury SW 1972 The distribution and storage of vitamin $\mathrm{D}$ and its metabolites in human tissue. Clin Sci 43:413

16. Nordin BEC 1976 Nutritional considerations. In: Nordin BEC (ed): Calcium, Phosphate and Magnesium Metabolism, Edinburgh, Churchill Livingstone, pp 1-36 Chap I.

17. Perkin RM, Kaminetzky HA, Newton M, Pritchard JA 1972 Maternal nutrition: a selective review of clinical topics. Obstet Gynecol 40:6773

18. Ross R, Care AD, Taylor CM, Pelc B, Sommerville BA 1979 The transplacental movement of metabolites of vitamin $D$ in the sheep. In: Norman AW, Schaefer K, Herrath DV, Grigoleit H, Coburn JW, DeLuca HF, Mawer EB, Suda T (eds): Vitamin D, Basic Research and Its Clinical Application. New York, Walter de Gruyter, pp 341-348

19. Saudi Arabian Meterological Department 1981 Annual Report. Riyadh, Ministry of Aviation

20. Sedrani SH, Elidrissy ATH, Al Arabi KM (1983) Sunlight and vitamin D status in normal Saudi subjects. Am J Clin Nutr 38:129

21. Stamp TCB, Haddad JG 1977 Comparison of oral 25-hydroxycholecalciferol, vitamin $\mathrm{D}$ and ultraviolet light as determinants of circulating 25-hydroxyvitamin D. Lancet 1:1341

22. Turton CWG, Stanley P, Stamp TCB, Maxwell JD 1977 Altered vitamin D metabolism in pregnancy. Lancet 1:222

23. Watney PJM, Chance GW, Scott P, Thompson JM 1971 Maternal factors in neonatal hypocalcaemia-a study in three ethnic groups. Br Med J 2:432

24. Woodhouse NJY, Norton WL 1982 Low vitamin D levels in Saudi Arabians. King Faisal SP Hosp Med J 2:3, 127

25. This research was supported by College of Science Research Centre to S. H. S., King Saud University, Riyadh.

26. The authors acknowledge the help of Dr. Zobayda Tawseef, the nursing staff of the Neonatal Unit, King Abdul Aziz University Hospital and the technical staff of the Biochemistry Department, College of Science.

27. Requests for reprints should be addressed to: Dr. Saleh H. Sedrani, Ph.D. Department of Biochemistry, College of Science, P.O. Box 2455, Riyadh, Saudi Arabia.

28. Received for publication May 15, 1983

29. Accepted for publication November 16, 1983. 